\title{
Public-Private Partnerships in Cambodia: Issues and Solution
}

\author{
Bun Eang Sar ${ }^{1 *}$, Meyka Chea ${ }^{2}$, Chanpisey Ung² \\ ${ }^{1}$ Faculty of Civil Engineering, Norton University, Phnom Penh, Cambodia \\ ${ }^{2}$ Ministry of Economy and Finance, Phnom Penh, Cambodia \\ Email: *sarbuneang@gmail.com
}

How to cite this paper: Sar, B. E., Chea, M., \& Ung, C. (2020). Public-Private Partnerships in Cambodia: Issues and Solution. Open Journal of Business and Management, 8, 1216-1225.

https://doi.org/10.4236/ojbm.2020.83078

Received: April 7, 2020

Accepted: May 19, 2020

Published: May 22, 2020

Copyright $\odot 2020$ by author(s) and Scientific Research Publishing Inc. This work is licensed under the Creative Commons Attribution International License (CC BY 4.0).

http://creativecommons.org/licenses/by/4.0/

\begin{abstract}
The projects via Public-Private Partnership (PPP) have been implemented in Cambodia since the decade 1993 mostly in energy sector using Build-Operate-Transfer (BOT) and Build-Own-Operate (BOO) Models where the procurement method followed an ad-hoc arrangement, absence of clear rule and regulation as well as unclear institutional responsibility to procure, manage, and monitor these projects. Lacking rule and regulation as well as non-clear enabling PPP policy caused many disadvantages for the public sector in implementing PPP projects. Nearly all the projects are unsolicited proposals and have been selected by using an ad-hoc arrangement and direct negotiation. The ad-hoc procedure not only transfers many risks to the government especially in term of financial risk-unforeseen contingent liability-due to no proper reviewing on the project proposal and contract term, but also the project implementation and monitoring mechanism is unclear, and no efficient. However, Cambodia still considers using PPP as the best alternative option of financing on infrastructure development. This is because, on the one hand, the demand of infrastructures has been gradually increased notably in road sector while the government budget is limited, and on the other hand, PPP brings the innovation and increases the quality of infrastructure or service and provides better value-for-money. That is why, in order to successfully prepare and manage PPP projects in the current context of economy growth, Cambodia established an enabling PPP policy, and standard operation procedure (SOP), and also proposed the PPP law to govern, promote and facilitate in the manner of effectiveness, efficiency, transparency, fairness and accountability of PPP projects. This paper aimed at raising the challenges of implementing PPP projects without comprehensive PPP framework.
\end{abstract}

\section{Keywords}

PPP, Ad-Hoc Arrangement, PPP Framework, Infrastructure, Contingent 
Liability

\section{Introduction}

The development of infrastructure is one of the critical factors of Cambodia in order to maintain and leverage economic growth. Cambodia has invested in infrastructure based on financing from three main sources: national budget, the budget from the development partners, and a small portion of budget from private sector. Due to the huge demand of such infrastructure, these financial resources are not sufficient. According to Asian Development Bank and Agence Française pour le Dévelopement (2012), the total investment need in infrastructure of the country was estimated to be in the range of $\$ 12$ billion - $\$ 16$ billion from 2013 to 2022 in which the private sector capital investment rate is approximately $6 \%$ of gross domestic product per year.

To deal with this issue, Cambodia pays more attention to private participation considering that private sector is an engine for growth (Royal Government of Cambodia, 2018), and latterly chose an alternative option of financing on public infrastructure investment, so-called PPP mechanism-it is non-privatization nor public traditional procurement-where there is no unique definition for it. Actually, definition of PPP varies from country to country due to political, economic, and social environment context (Eliza, 2015). One of the definition of the term PPP is that PPP broadly refers to long-term contractual partnership between the public and private sector agencies specifically targeted towards financing, designing, implementing, and operating infrastructure facilities and services that were traditionally provided by the public sector in which the appropriate and mutually agreed allocation of resources, risks, and returns are shared among them (Vinod, 2014). Although PPP has many definitions, it has the common characteristic as follow: 1) a private partner provides the design, construction, financing and operation in return for payment either from users of the infrastructure or from the public client its self, 2) public and private partners share risks and jointly manage them through better utilization of resources and improved project control, and 3) PPP projects are usually based on a long-term contract to encourage innovation and low life cycle cost (Zhang \& Chen, 2013).

Based on literature review, it is found that PPP is not new but it has been around for few centuries, especially in France during $16^{\text {th }}$ and $17^{\text {th }}$ century (Zhang \& Chen, 2013). However, it has been observed that for over two recent decades, many governments have initiated PPP to let the private sector take over the responsibility for developing infrastructure and providing public service (Eval et al., 2013). According to Zairol et al., 2014, PPP has become increasingly popular in many countries since the 1990s. PPP has become a popular way for government to engage private actors in the delivery of government infrastructure and services with the aim of increasing quality and providing better val- 
ue-for-money.

PPP has been used in both economic and social sector. The developed countries have implemented PPP in a variety of sectors including transportation, telecom-munication, power, water, sanitation, health, education, and correction facilities among others (Lina et al., 2016). Recently, PPP has become the preferred mode for construction and operation of commercially viable infrastructure projects in sectors such as highways, airports, ports, railways, and urban transit system (Vinod, 2014).

The successful PPP project relies on comprehensive PPP framework of the country. However, the implementation of PPP projects has made via the ad-hoc arrangement due to absence of specific law, rule and regulations resulting of non-consistence with international best practice (Royal Government of Cambodia, 2016). Lacking clear PPP framework caused many challenges for the implementation of PPP projects in Cambodia.

The present paper is aimed at providing, on the one hand, the issues of implementation of PPP projects in Cambodia due to inadequate PPP framework, and on the other hand, the solution that is the update of the development of this framework including PPP policy, PPP law, rule and regulation, and institutional arrangement for implementing PPP projects.

\section{Issues of Implementing PPP Projects in Cambodia}

There has been found that there are numerous of challenges in implementing PPP projects in Cambodia, among them the legal framework, institution mechanism, and capacity and awareness of line ministries are the main critical factors.

Firstly, absence of comprehensive legal framework is the principal issue. So far, Cambodia has implemented PPP projects based mainly on law on concession adopted in 2007 (Royal Government of Cambodia, 2007), and law on investment adopted in 1994 (Royal Government of Cambodia, 1994). Yet the law on concession has been adopted, the sub-decree to implement the law has never been achieved. Deeply review on the law on concession, we found that it is mostly inconsistent with international best practice regarding PPP scheme due to many reasons, for example, the role of assessing PPP project proposals and determination of government support is not clear; and only the revenue-based payment is allowed that is not the case because PPP payments could have another methods such as availability based payment, the procurement rules to select the private proponent are also not yet clear, the concessionaire shall finance for the implementation of the project at its own cost and risk, unclear institution to manage PPP project, etc. (Royal Government of Cambodia, 2007). Even though there were inadequate rule and regulation, non-clear institutional arrangement to implement, manage and monitor PPP projects, Cambodia has run since the decade 1990 the PPP projects in energy sectors, airport, bridges, and road sector as shown in Table 1 (UNESCAP; AFEO; MPWT; VINCI). However, 
Table 1. Implemented PPP project in Cambodia.

\begin{tabular}{|c|c|c|c|c|}
\hline No & Project's name & $\begin{array}{l}\text { Project's } \\
\text { capacity }\end{array}$ & Contract & $\begin{array}{l}\text { Commercial } \\
\text { operation date }\end{array}$ \\
\hline I & Energy $^{\mathrm{a}, \mathrm{b}}$ & & & \\
\hline 1 & Kirirom 1 Hydropower & $12 \mathrm{MW}$ & BOT & 2002 \\
\hline 2 & Ochum 2 Hydropower & $1 \mathrm{MW}$ & - & 1993 \\
\hline 3 & Coal Plant & $10 \mathrm{MW}$ & BOO & 2010 \\
\hline 4 & Kamchay Hydropower & 194.1 MW & BOT & 2011 \\
\hline 5 & Kirirom 3 Hydropower & $18 \mathrm{MW}$ & BOT & 2013 \\
\hline 6 & Coal Power Plant & $100 \mathrm{MW}$ & $\mathrm{BOO}$ & 2013 \\
\hline 7 & Atay Hydropower Plant & $120 \mathrm{MW}$ & BOT & 2014 \\
\hline 8 & Lower Stung Russei Chrum Hydropower & $338 \mathrm{MW}$ & BOT & 2014 \\
\hline 9 & Coal Power Plant & $270 \mathrm{MW}$ & $\mathrm{BOO}$ & 2014 \\
\hline 10 & Tatay Hydropower & $246 \mathrm{MW}$ & BOT & 2015 \\
\hline 11 & Lower Se San 2 Hydropower & $400 \mathrm{MW}$ & BOT & 2018 \\
\hline 12 & Solar Farm & $10 \mathrm{MW}$ & $\mathrm{BOO}$ & 2018 \\
\hline II & Road $^{c}$ & & & \\
\hline 1 & Phnom Penh-Sihanoukville Expressway & 4 lanes & BOT & 2023 \\
\hline III & Airport $^{\mathrm{d}}$ & & & \\
\hline 1 & Phnom Penh International Airport & - & Concession & 1995 \\
\hline 2 & Siemreap Airport & - & Concession & 1995 \\
\hline 3 & Sihanoukville Airport & - & Concession & 2016 \\
\hline
\end{tabular}

a Ministry of Mines and Energy of Cambodia. Workshop on SDG7 Implementation in Asia and Pacific: National Expert SDG Tool for Energy Planning (NEXSTEP) and the Asian Pacific Energy Resources Modeling Platform, 2019. ' Ministry of Mines and Energy of Cambodia. Energy Outlook in Cambodia. ${ }^{\mathrm{c}}$ Ministry of Public Works and Transport of Cambodia, 2019. ${ }^{\mathrm{d}}$ Vinci-Airport Cambodia.

the selection and approval of these projects has been made via the ad-hoc arrangement in which the inter-ministerial committee was created and headed by the Council for the Development of Cambodia (CDC) whose members are from implementing agencies, relevant line ministries as well as local authorities. Using this arrangement not only transfers much risks to the government especially financial risk-unforeseen contingent liability-due to no proper review on the project proposal and contract, but also the project implementation and monitoring mechanism is unclear, and no efficiency. In addition, many potential investors might be reluctant to invest in this kind of project concerning the unfair treatment of selection, and unanticipated project risk for both legal and financial aspect. In the contrast, this arrangement provides some advantage due to the simplification and shortening of the approval process leading to earlier construction compared to the conventional public procurement.

Meanwhile the PPP in energy sectors has been successfully implemented, there have been some projects in road sectors, as shown in Table 2 (Khmertime, 2016; Khmertime, 2017a, Khmertime 2017b), has been terminated by the government 
Table 2. Terminated projects.

\begin{tabular}{cccccc}
\hline No & Project's name e,f,g $^{\text {Contract }}$ & $\begin{array}{c}\text { Concession } \\
\text { period }\end{array}$ & $\begin{array}{c}\text { Commercial } \\
\text { operation date }\end{array}$ & $\begin{array}{c}\text { Termination } \\
\text { date }\end{array}$ \\
\hline 1 & Koh Kong Bridge & BOT & 30 years & 2002 & 2017 \\
2 & Prek Phnov Bridge & BOT & 30 years & 2010 & 2017 \\
3 & National Road 4 & MOT & 35 years & 2001 & 2016 \\
\hline
\end{tabular}

${ }^{\mathrm{e}}$ Khmertime, 2017a; ${ }^{\mathrm{f}} \mathrm{Khm}$ ertime, 2017b, ${ }^{\mathrm{g}} \mathrm{Khm}$ ertime, 2016.

due to unspecific reason. The ministry of economy and finance is responsible for the compensation to the private partners. The repayment to the private sectors has been made without clear official formulas. The termination not only impacts on government budget but also makes a bad signal to the private sector.

Secondly, Cambodia has no clear institutional framework until the central PPP unit (CPU) has been established in 2017 within the Ministry of Economy and Finance. In the pass, CDC played the important role in facilitating, promoting, and approving the PPP projects. Its main role is one window service body, i.e. the mega infrastructure project proposals including PPP projects have to go through CDC channel. The inter-ministerial committee chaired by CDC reviews, assesses, selects, and approves PPP projects. In addition, CDC also provides government incentive, for example tax and import duty exemption, to private company for qualified investment projects. CDC also set necessary legal documents to be fulfilled by investors-including application form, check list of required documents, and transparent fee-in order to ease the application of investment proposal in Cambodia. Furthermore, CDC brings the local projects to the global market and communicates with potential investors to invest in Cambodia. Without clear institutional mechanism, the ad-hoc arrangement has been used for approval of PPP projects.

However, it is in 2016 that Cambodia has established the Inter-ministerial Committee on PPPs (IMC) to play a role as the overall decision-making body on PPP policy, regulations and projects (Royal Government of Cambodia, 2016). The IMC chaired by Ministry of Economy and Finance and its members are from priority line ministries. Later on, in 2017, the CPU has been set up in the Ministry of Economy and Finance to play a role as the Secretariat to the IMC. The mission of CPU is to promote, coordinate, and manage PPP projects in an innovative and effective manner to contribute to supporting sustainability of long-term economic growth and increasing Cambodia's competitiveness; and pushed line ministries to create their own dedicated PPP Units to facilitate project identification, selection, prioritisation, preparation, procurement, and implementation. So far, some of the line ministries have created only its PPP working groups. There are not yet PPP units in the line ministries.

Thirdly, even though many PPP projects have been implemented in the country, the capacity of government institution and awareness of line ministries in 
PPP scheme is very limited. The projects have been approved without deeply review on the relevant risks especially financial risks for the government. In addition, there is no review on legal risk of the contract. The contingent liability is not estimated. However, in the last five years, due to the effort of the ministry of economy and finance in coordinating with the development partners in providing training on PPP, line ministries have been mostly aware of PPP concept. The capacity of government officials in preparing the projects has been significantly improved. However, the understanding on the financial model analysis, and risk analysis as well as the ability to review the project proposal and project negotiation is limited.

\section{Update of PPP Framework in Cambodia}

PPP framework in Cambodia covers policies, laws, rules and regulations, and institution arrangement as well as financing mechanism.

\subsection{Policy to Support PPP Mechanism}

Began with the first mandate of the national assembly legislated in 1993, Cambodia has promoted and encouraged private sector to participate in public infrastructure investments by setting out necessary policies-triangle strategy, rectangular strategy, national strategic development plan, public financial law, and Cambodian industrial development policy-and legal instruments as well as other necessary measures to strengthen and widen partnerships with all partners.

Furthermore, in order to set clear mechanism for successful implementing PPP projects, Cambodia has developed in 2016 its Policy Paper on PPP (Royal Government of Cambodia, 2016) in order to create an enabling environment, promote and encourage private sector and financial institutions to take part in public infrastructure investments. These are some reasons that Cambodia need to have its own policy on PPP in order to attract private sector in investing on public infrastructure project. Firstly, it is found that in the new economic development context, Cambodia need to invest in a huge amount of infrastructure amid the government budget is very limited. Secondly, Cambodia recognizes that the participation of private sector in public investment brings about not only additional financing, but also knowledge, knowhow, and technology to public sector leading to implement the public infrastructure projects in a more innovative and effective manner. Thirdly, the decline of loans with high concessionality when Cambodia reached a lower-middle-income country in 2015, with the prospect of attending the status of upper-middle-income country in 2030, and finally a high-income country in 2050. Fourthly, Cambodia cannot anymore, in the current situation, continue using the ad-hoc arrangement in selecting and procuring the public investment projects due to uncontrollable fiscal issue in the future-the implicit contingent liability.

The PPP Policy sets out the strategic measures for immediate, medium-term, 
and long-term period. The immediate measures are to 1) Review and development of legal framework and operational management procedures, 2) Development of financial support mechanism, 3) Develop and identify of institutional mechanism, and 4) develop institutional capacity and human resource.

For the immediate measures, the policy allows only the user-based payment without any guarantee from the government. In this period, the sectors that are suitable for PPP are mostly in 1) Transportation system such as roads, bridges, railroads, ports, and airports; 2) Production, transmission and distribution of electricity; 3) Production, supply and distribution of clean water; 4) Development, modernization of markets and public car parks or public commercial centers; 5) Development of public infrastructure in industrial zones; 6) Waste collection and management services; 7) Waste water treatment and sewage systems; 8) Vocational skill development; 9) Social housing infrastructure; 10) Tourist infrastructure such as tourist attraction sites, and museums.

For the medium term, Cambodia may review possibility of using an availability-based payment and hybrid payment along with updating on priority project list based on actual economic context by reviewing possibilities to include a number of additional priority sectors such as infrastructure for gas and petroleum sector; telecommunications, information and communications technology; irrigation system and agriculture infrastructure; and other priority sectors.

In the long-term, Cambodia may consider social sector such as public health, and education and sports infrastructure.

Overall, the PPP policy is a key roadmap for Cambodia to fully establish and implement comprehensively and fully interlinked system to manage PPP projects in accordance with international best practice.

\subsection{PPP Legal Framework}

There has been not yet specific PPP law in Cambodia. But the PPP law has been initiated by the Ministry of Economy and Finance and it is in the stage of development. There is also no specific rule and regulation to implement PPP projects. However, the sub-decree on BOT has been adopted in 1998 to facilitate the implementation of PPP projects (Royal Government of Cambodia, 1998).

In this regard, Ministry of Economy and Finance has initiated in reviewing the existing laws leading to draft the PPP law based on international experiences, and inputs from line ministries, experts, and relevant stakeholders. The purpose of this law is to govern, promote and facilitate the effective, efficient, transparent, fair and accountable use of PPP mechanism in public investment projects for socio-economic development of Cambodia. Achieving PPP law not only shows the commitment of government to PPP, but also addressing the PPP-related issues leading to increasing the confidence for private sector.

The PPP draft law has been double consulted among line ministries, private sector, financial institutions, and the development partners. The law is expected to adopted in the beginning of the year 2021. 


\subsection{Rules and Regulations}

In order to fully implement the PPP projects in the manner of fairness, transparency, effectiveness, competitiveness, and ensuring value-for-money, Cambodia has finalized its SOP for PPP. The SOP set out the main procedures, stages and requirements to be followed for the whole PPP projects cycle in which the roles and responsibility of institutions and the decision-making and approvals bodies have been specified. The SOP contains, as publicly mentioned in various consultation workshop among public and private sectors, the following guidelines (Korean Development Institute): project selection guidelines, project development fund guidelines, feasibility study guidelines, financial analysis guidelines, value-for-money analysis guidelines, PPP contract template, PPP procurement manual, government support measures guidelines, risk management framework guidelines, and contract management guidelines. These documents are finalized in draft and are waiting for implementing by sub-decree whenever the PPP law has been adopted.

\subsection{Institutional Arrangement}

It is in 2016 that Cambodia established the IMC on PPPs to play a role as the overall decision-making body on PPP policy, regulations and projects. The IMC chaired by Ministry of Economy and Finance and its members are from priority line ministries. Later on, in 2017, the CPU has been set up in the Ministry of Economy and Finance to play a role as the Secretariat to the IMC. The mission of CPU is to promote, coordinate, and manage PPP projects in an innovative and effective manner to contribute to supporting sustainability of long-term economic growth and increasing Cambodia's competitiveness; and pushed line ministries to create their own dedicated PPP Units to facilitate project identification, selection, prioritisation, preparation, procurement, and implementation. So far, some of the line ministries have created only its PPP working groups. There is not yet PPP units in the line ministries.

\section{Conclusion}

PPP projects have been implemented in Cambodia since 1990s in energy sector, road, and airport via BOO, BOT, and Maintenance-Operate-Transfer (MOT) model. There has been no any law nor full regulations to govern these PPP projects. The projects preparations have been done based on the law on concession and other complemented laws that are not mainly related to PPP implementation as required by international best practice. So far, the procurement of these projects has been made via the ad-hoc arrangement without paying attention to unforeseen fiscal risk-contingent liability-for the public sector due to limited capacity of implementing agency in reviewing the project proposal. Following the ad-hoc arrangement might not only face to contingent liability event for the public sector, but also unclear institution responsibility for the whole project cycle. Owing to Unclear rules and regulation as well as institution to go- 
vern PPP projects, the number of unsolicited proposals has been increased and the capacity of line ministries has never been improved due to less practice in the real project.

To avoid these issues amid the need of the development of the infrastructure, the solution is that Cambodia has to develop its full PPP framework. Among them, the PPP policy was adopted in 2016; the draft SOP was completed in 2019, and the law on PPP is in the stage of drafting and reviewing in the current year 2020. At the same time, Cambodia has institutionalized central PPP unit in the ministry of economy and finance to coordinate with implementing agency for preparing, reviewing, and selecting the PPP projects.

In addition to the above-mentioned PPP legal framework, there are many key points to be taken into account in order to successfully implement and manage the PPP projects in Cambodia. Firstly, the capacity of government official needs to be strengthened. Secondly, the CPU should be more empowered and politically supported. Fourthly, the fiscal risks assessment and contingent liability quantification should be done for all PPP projects in which the project data base should be systematically computerized and the country risk as well as sectorial risks should be evaluated, and finally the government should not much welcome the unsolicited proposals but encourage line ministries to initiate the potential PPP projects for attracting private investors.

\section{Conflicts of Interest}

The authors declare no conflicts of interest regarding the publication of this paper.

\section{References}

AFEO.

http://afeo.org/wp-content/uploads/2018/09/Energy-Outlook-in-Cambodia-BEC.pdf

Asian Development Bank and Agence Française pour le Dévelopement (2012). Assessment of Public-Private Partnerships in Cambodia: Constraints and Opportunity. The Philippines.

Eliza, L. Y. W. (2015). How Shall We Examine and Learn about Public-Private Partnerships (PPPs) in the Health Sector? Realist Evaluation of PPPs in Hong Kong. Social Science \& Medicine, 147, 261-269. https://doi.org/10.1016/j.socscimed.2015.11.012

Eva, I. H., David, J., K., \& Patricl, W. S. (2013). Public-Private Partnership versus Traditional Procurement: An Experimental Investigation. Journal of Economic Behavior \& Organization, 89, 145-166. https://doi.org/10.1016/j.jebo.2011.05.001

Khmertime (2016).

https://www.khmertimeskh.com/34554/pm-removes-tolls-from-national-road-4/

Khmertime (2017a).

https://www.khmertimeskh.com/84897/state-buys-bridge-lyp-group/

Khmertime (2017b).

https://www.khmertimeskh.com/88752/state-buys-koh-kong-bridge/

Korean Development Institute. 
http://www.kdi.re.kr/kdi_eng/common/seminar_down.jsp?fno=\%2Ftx2LXQlhGLfPel MWR\%2FfRg\%3D\%3D\&fty=IKKLJlukyUcpG4EmUThiYg\%3D\%3D

Lina, M. S., Carlos, A. A., \& Jose, L. P. (2016). A Proposal Risk Allocation in Social Infrastructure Project Applying PPP in Colombia. Procedia Engineering, 145, 1354-1361. https://doi.org/10.1016/j.proeng.2016.04.174

MPWT. http://www.mpwt.gov.kh/en/press/6321

Royal Government of Cambodia (1994). Law on Investment. Phnom Penh, Cambodia.

Royal Government of Cambodia (1998). Sub-Decree on Build-Operate-Transfer Contract. Phnom Penh, Cambodia: Royal Government of Cambodia.

Royal Government of Cambodia (2007). Law on Concession. Phnom Penh, Cambodia.

Royal Government of Cambodia (2016). Policy Paper on Public-Private Partnerships for Public Investment Project Management 2016-2020. Phnom Penh, Cambodia: Ministry of Economy and Finance.

Royal Government of Cambodia (2018). Rectangular Strategy "Phase 4" for Growth, Employment, Equity and Efficiency: Building the Foundation toward Realizing the Cambodia Vision 2050. Phnom Penh, Cambodia: Sixth Legislature of the National Assembly.

UNESCAP.

https://www.unescap.org/sites/default/files/Operationalizing\%20NEXSTEP\%20at\%20n ational\%20level\%20_\%20Cambodia_Mr.\%20Sareth\%20Nong.pdf

VINCI. http://www.vinci-airports.com/en/airports/phnom-penh-airport

Vinod, N. S. (2014). PPP from Asia and Africa Perspective towards Infrastructure Development: A Case Study of Greenfield Bangalore International Airport, India. Procedia-Social and Behavioral Sciences, 157, 285-295. https://doi.org/10.1016/j.sbspro.2014.11.031

Zairol, A. A., Richard, P. H., \& Dilanthi, A. (2014). Public-Private Partnership in Disaster Management in Developing Countries: A Conceptual Framework. Procedia Economics and Finance, 18, 807-814. https://doi.org/10.1016/S2212-5671(14)01006-5

Zhang, X. Q., \& Chen, S. (2013). A Systematic Framework for Infrastructure Development through Public-Private Partnerships. IATSS Research, 36, 88-97.

https://doi.org/10.1016/j.iatssr.2012.11.001 